Review Article

\title{
Host Receptor Immunomodulation in Response to Shigella Surface Antigens: An Insight for Vaccine Development
}

\author{
${ }^{1}$ Ashim K. Bagchi, ${ }^{1}$ Rushita A. Bagchi, ${ }^{2}$ Dipak K. Hens, \\ ${ }^{3}$ Fahmida Jahan, ${ }^{4}$ Pragna H. Parikh and ${ }^{5}$ Dhira Rani Saha \\ ${ }^{I}$ Department of Physiology and Pathophysiology, University of Manitoba, Winnipeg, Manitoba, Canada \\ ${ }^{2}$ Sonamukhi Degree College, University of Burdwan, Bankura, West Bengal, India \\ ${ }^{3}$ Department of Biochemistry and Medical Genetics, University of Manitoba, Winnipeg, Manitoba, Canada \\ ${ }^{4}$ Department of Zoology, The Maharaja Sayajirao University of Baroda, Vadodara, Gujarat, India \\ ${ }^{5}$ National Institute of Cholera and Enteric Diseases, Kolkata, West Bengal, India
}

Article history

Received: 28-12-2014

Revised: 21-05-2015

Accepted: 29-05-2015

Corresponding Author:

Ashim K. Bagchi

Department of Physiology and

Pathophysiology, University of

Manitoba, Winnipeg, Manitoba,

Canada

Email: bagchi.ashimkumar@gmail.com

\begin{abstract}
Shigellosis, caused by Shigella is the most common cause of bacillary dysentery. The disease is associated with high morbidity and mortality rate owing to its multiple drug resistance. Hence recovery from the disease would primarily depend on the development of an effective immune-modulator for strong mucosal immune response. The role of cellular immunity may be a critical factor in protection against shigellosis as Shigella remains an intracellular pathogen during most of its life-cycle. Development of a potent immunomodulator may provide strong and longlasting immunity to shigellosis. In this review, we have attempted to highlight the disease dimension and its deviation due to the effect of various Shigella surface antigens that would help in the development of an effective immune response. Cellular innate immune modulation will be a new generation target for the development of mucosal candidate vaccines where proper receptor activation such as Toll-Like Receptors (TLRs), Cytokine Receptors (CyRs) and/or T-Cell Receptors (TCRs) on the host cell could be aimed at producing mucosal immunity. An effort has been made to better understand the effect of these immunomodulators against shigellosis by way of modulating the host immune mechanism to Shigella outer membrane component.
\end{abstract}

Keywords: Shigella, Surface Antigens, Host Cell Receptors, Immunomodulation, Immune Response

\section{Introduction}

Bacillary dysentery is a highly contagious enteric bacterial infection. It is the most important cause of high morbidity and mortality among infants and young children in both developed and developing countries worldwide. It has been estimated that about 200 million episodes occur per year in children up to 5 years of age, resulting in as many as 3-4 million deaths (Ferreccio et al., 1991; Lindberg and Pal, 1993). Among the entire toll of diarrheal diseases, five million people suffer annually from Shigella infection in developing countries and nearby about 700,000 individuals die from this infection (WHO, 2005; Kotloff et al., 1999). On an around 10\% of entire child deaths below 5 years are responsible due to shigellosis (Ferreccio et al., 1991; WHO, 2005).
Different Shigella species (spp.) and their serotypes vary in their geographical distribution- some being more prevalent than the other in a specific region in the world (Table 1). The disease is associated with poor hygienic standards and malnutrition. Shigella is usually transmitted directly from person-to-person by the fecaloral route. Shigella can also be transmitted through food or water contaminated by human waste. $40 \%$ of adults and $20 \%$ of children develop infection from epidemic household contacts (CDC, 2001). The clinical signs of shigellosis range from mild diarrhea to severe dysentery with frequent passage of bloody, mucoid, small-volume stool accompanied by fever, abdominal pain and tenesmus at the acute stage (Keusch, 1986; Keusch et al., 1988). Clinical symptoms in elderly above $65 \mathrm{yr}$ are as severe as in children (Daniel and Lawrence, 2003). 
Table 1. Geographical distribution of Shigella serotypes

\begin{tabular}{llll}
\hline & & Number of \\
Shigella species & Serogroup & serotypes & Geographical distribution (predominant) \\
\hline S. dysenteriae & A & 15 & Central America, South and South-East Asia, Sub-Saharan Africa \\
S. flexneri & B & 14 & Asia, Europe, Latin America \\
S. boydii & C & 20 & South Asia, Sub-Saharan Africa, Middle East \\
S. sonnei & D & 1 & East Asia and Pacific, Australia, East Europe, Middle East, North and Latin America \\
\hline
\end{tabular}

Sometimes, it creates havoc in elderly than in children for the development of Shigella bacteremia (Morduchowicz et al., 1987). Shigella is extremely infectious bacteria and ingestion of just 10 organisms is enough to cause severe diarrhea and dehydration (Dupont, 1989). Usually, the incubation period varies from 6 to 96 hours with the infecting strains. The infection is self-limiting in healthy hosts but in malnourished children, the disease persists over days to weeks or even last for several weeks and months.

Infection caused by $S$. dysenteriae 1 strain producing Shiga toxins, a potent cytotoxin have a tendency towards a serious severity like hemolytic uremic syndrome, which has a high mortality rate (Dupont, 1990) as compared to the other non-toxin producing strains.

Many cases of bacterial dysentery improve without antibiotic treatment. In fact, in healthy individuals, the infection may subside on its own within 4-7 days, with home remedies and oral rehydration. Therefore, drugs are needed only for the treatment of moderate or severe disease. Choice of antibiotic is based on the type of bacteria found in the geographical area and on laboratory test results. WHO (1997) recommends ampicillin, sulfa derivatives such as Trimethoprim-Sulfamethoxazole (TMP-SMX) trade name Bactrim, or fluoroquinolones such as Ciprofloxacin, which are currently used in adults; however these drugs are not approved by FDA for use in children).

Antibiotic is virtually advised for every treatment during shigellosis (Oldfield and Wallace, 2001; Dhodapkar et al., 2008). First line choice of antibiotic for Shigella therapy is the quinolone family of drugs. Murphy et al. (1993) suggested that ciprofloxacin should be used orally in adult shigellosis. Another study showed that loperamide, an anti-motility agent, leads to quicker improvement without prolonging Shigella elimination. Azithromycin has similar efficacy to ciprofloxacin (82\% for azithromycin and $89 \%$ for ciprofloxacin) (Khan et al., 1997; Taneja, 2007) and showed intracellular penetration and moderate in vitro Shigella activity. With increasing quinolone resistance, other agents have been explored, such as first- and second-generation cephalosporins that are active in vitro but have proven to be a disappointment in clinical use (Oldfield and Wallace, 2001). According to Anh et al. (2001) about $80 \%$ of the Shigella strains tested were resistant to ampicillin, chloramphenicol, oxytetracycline, trimethoprim and sulfonamides. Changing patterns of antimicrobial susceptibility of such Shigella serotypes isolated from children with acute diarrhea suggest that multidrug resistance causes over a million deaths in developing countries (Mamatha et al., 2007). Chloramphenicol or nalidixic acid has now been recommended for severe dysentery, as it is low-cost, effective and safe for children. However, some strains of Shigella showed 3-5\% resistance to nalidixic acid and norfloxacin (Anh et al., 2001). In Fiji Islands, only intravenous antibiotics sensitive to Shigella like, ceftriaxone and cephalothin could be advised in case, if the patients are unable to take oral drugs (Watson, 2001) whereas, cephalothin was found to have $57.1 \%$ resistance to all Shigella sero-groups in Ethiopia (Mache, 2001). Gentamycin, polymyxin B and nalidixic acid were found to be the drugs of choice for shigellosis. Continuous surveillance of multidrug resistant strains is very important in order to understand the changing patterns of antibiotic susceptibility (Doyle, 2014; CDCR, 2015; Srinivasa et al., 2009) as well as mutations in serogroups. Change in drug resistance pattern is associated with the change in serogroup genetic makeup. Thus, antibiotic treatments following development of resistance sometimes may develop inability to produce antibodies in patient and induce immunity.

Over the past few decades, the numbers of multi-drug resistant Shigella strains have progressively increased treatment failure and mortality (Doyle et al., 2013; WHO 2014). Thus, an alternative approach using immunomodulators could be a useful strategy to treat patients with multi-resistant Shigella infection. The use of these immunomodulators could possibly trigger a biased antigen-specific signal to increase immune functions.

Specific and type-specific immunity to Shigella infection is acquired after dysentery but is relatively weak and for a short duration. Therefore, the disease may recur many times due to drug resistance and in some cases, may become chronic (Hens et al., 2005). Targeting host cellular receptors in order to induce typespecific humoral or cellular immune response could be beneficial in achieving immunity to shigellosis and overcome the disease burden in developing countries. Immune responses against Shigella surface antigens like Lipopolysaccharide (LPS) molecules, Outer Membrane Proteins (OMPs) and the invasion plasmidcoded proteins (Ipa's) are specific and most pronounced (Oaks et al., 1986; Oberhelman et al., 1991). Changes in the secretory immune system of the intestinal mucosa have been shown to cause primary mucosal immunity. These secretory antibodies could help in the activation of intra-epithelial lymphocytes (Phalipon et al., 2002), which could possibly trigger 
release of pro-inflammatory cytokines such as Interleukin (IL)-1 $\beta$, IL-6, Transforming Growth Factor (TGF)- $\beta$ and Interferon (IFN)- $\gamma$ that are associated with the degree of infection (Islam et al., 1997; Raqib et al., 1995a). However, the levels of receptor expression are down-regulated and inversely correlated with the severity of the disease (Raqib et al., 1995b). It is now being said that many inflammatory reactions occur in order to acquire specific immunity against shigellosis and are mediated by a broad range of cytokines released from the cytokine-producing cells.

Local antibodies against LPS and Ipa have been detected in intestinal secretions of Shigella- infected monkeys (Dinari et al., 1987; Oaks et al., 1986) and patients (Oberhelman et al., 1991). Most of the epidemiological and clinical data suggest that increased levels of serum antibodies are good indicators of natural or experimental stimulation by immuno-dominant antigens and in turn could induce effective immunity (Cohen et al., 1992; Oberhelman et al., 1991). An approach towards the immunoprophylactic measures against shigellosis may be achieved by way of elucidating a relation between pathogenesis (Navarre and Zychlinsky, 2000; Perdomo et al., 1994; Chakraborti and Sinha, 1994) and host immune mechanism using bacterial outer membrane components such as LPS, Ipa's and OMPs as potent immunomodulators or by modulating cellular innate system targeting specific receptors such as Toll-Like Receptors (TLRs), Cytokine Receptors (CyRs) and/or T-Cell Receptors (TCRs).

\section{Shigella Surface Antigens: Immunomodulators}

Variations in the Shigella surface antigens make it most challenging for the development of candidate vaccine (Ashkenazi et al., 1999; Cohen et al., 1988; Robbins et al., 1992). A strategy to develop pentavalent anti-O-antigens from five different Shigella spp. was undertaken to provide global immunity to Shigella infection (Iankov et al., 2004). Although there has been increased interest of understanding the protective efficacy of a single- or multi-serotype OMPs (Mitra et al., 2012), their sensitivity and specificity to species-specific infection needs to be considered. Several experimental evidences have shown the generation of humoral as well as cellular immune response against various Shigella surface antigens and/or super antigens (Acha-Orbea, 1993; Beckman et al., 1994; Herman et al., 1991; Witkowska et al., 1986). A strong antibody response to LPS and Ipa antigens has been reported earlier (Cam et al., 1992; Oberhelman et al., 1991; Passwell et al., 1995) that confers protection against shigellosis (Cohen et al., 1988; Mitra et al., 2012; Passwell et al., 1995). Two novel virulence loci, mxi $A$ and $m x i B$, in $S$. flexneri 2a facilitating excretion of IpaB have been shown to modulate protection against the disease (Andrews et al., 1991).
Disease dimension and its deviation due to the effect of these antigens have not been systematically analyzed in order to have an effective humoral as well as cellular immunity to shigellosis. LPS-induced T-cell responses to produce cytokine as well as other cytokine-producing cell responses were also described earlier (Sieling et al., 1995). In contrast, these LPS molecules as an antigen itself cannot induce an effective cellular immune response since LPSs are T-independent antigens which require CD1 molecules to be recognized by $\mathrm{T}$-cells (Beckman et al., 1994; Sieling et al., 1995). Besides, LPS and OMPs also play an important role in adherence, invasion, serum resistance and resistance to phagocytosis (Buchanan and Pearce, 1979). Moreover, OmpA of $S$. flexneri $2 a$ has been found to induce a significant protective immune response in a mouse model (Pore and Chakrabarti, 2013; Pore et al., 2011).

Many strategies have been implemented to mitigate the pathogenicity of Shigella by gene manipulation in lipid A biosynthesis e.g., htrB and $m s b B$ (D'Hauteville et al., 2002). Serological tests have also revealed high crossreactivity among these surface components of different groups of gram-negative bacteria and their species (D'Hauteville et al., 2002; Peterfi et al., 2007). Despite their strong immunogenicity, there are many limitations in using these candidates as a vaccine (Kaminski and Oaks, 2009; Kuehn and Kesty, 2005). One of the major drawbacks is that their specificity is limited to a particular species or sub-species rather than inducing global immune response to the disease. Indeed there is a need to identify a strong immuno-dominant component to trigger the host defense system against shigellosis. Most of the identified proteins have a univalent epitope and essentially participate in T-cell activation for antibody synthesis via peptide-H2 complex. Thus, proteins may be considered as T-cell dependent immunogens that can possibly generate exclusive antigen-specific immunoglobulins (Pore et al., 2009). Moreover, ShiA, the product of a novel Open Reading Frame (ORF), has also been shown to reduce inflammatory responses where T-cells play a major role in achieving immunity to shigellosis (Ingersoll and Zychlinsky, 2006). A genetic mutant of ShiA ( $\Delta$ shiA) has been shown to induce polymorphonuclear cell migration resulting in increased inflammatory response (Ingersoll and Zychlinsky, 2006; Peterfi et al., 2007). It is now suggested that ShiA could be used to modulate immune system (Ingersoll and Zychlinsky, 2006). Such purified antigenic protein fraction or factors in the ORFs may facilitate immunomodulatory effects in monitoring antigenicspecific signals and ascertain its immunoprophylactic nature against such infection.

\section{Immunomodulatory Effect of Surface Antigens}

Earlier many Shigella spp. and their surface components have been identified and used as mucosal vaccine candidates (Barman et al., 2011; Iankov et al., 
2004; Kaminski and Oaks, 2009; Kuehn and Kesty, 2005; Mitra et al., 2012; Pore et al., 2009) but their immune-stimulatory effects were less defined. Lack of immuno-stimulatory features of the target candidates often does not elicit strong mucosal immunity (Borisova, 1999). Immunogenicity of the candidate vaccines is less described since available surface antigens exhibit weak epitope determinant sites and fail to induce antigenspecific responses. Immunomodulatory molecules are often predominantly derived from the pathogens that efficiently activate immune system leading to acquired host adaptiveness. There are yet many unknown facts that need to be explored before rationalized development of candidate vaccine for safety, immunogenicity and its efficacy. Thus it may require two basic components to verify the vaccine efficacy: First, an appropriate animal model to test the safety and immunogenicity of the candidate (Katz et al., 2004; Robbins and Schneerson, 1990) and, secondly, the presence of an appropriate carrier molecule (Beckman et al., 1994; Sieling et al., 1995).

Despite many efforts, there is a profound lack of immunomodulatory effect of the available surface antigens. The immunomodulatory effect of Shigella porin has been described to mediate antibody dependent B-cell responses (Alurkar and Kamat, 1997; Roy and Biswas, 1996). Small dose of $S$. flexneri OMPs has also been found to induce humoral as well as cell-mediated immune responses (Czarny et al., 1992; Sinha et al., 1992), whereas a higher dose suppresses Delayed Type Hypersensitivity (DTH) in mice (Chakrabarti and Sinha, 1994). Immuno-dominant components such as 38, 34, 23 and $20 \mathrm{kDa}$ of $S$. flexneri OMPs were also found to induce protective immune responses against shigellosis (Mukhopadhaya et al., 2003). Nevertheless, $34 \mathrm{kDa}$ OMPs of $S$. flexneri $2 \mathrm{a}$ was found to increase IL-12p70 activity by macrophage (Ingersoll and Zychlinsky, 2006) together with increased levels of serum IgG and IgA and other cytokines in both systemic and mucosal conditions (Arranz et al., 1992; Pore et al., 2011). Many subunits of conjugated vaccines have also been shown to cause limited peripheral antibody production (Camacho et al., 2011; Hartman et al., 1994; O'Hagan and Valiante, 2003; Robbins et al., 1992).

\section{Humoral Immune Response to Shigella Surface Immunomodulators}

Immunity to Shigella or other enteric pathogens is primarily mediated by secretory IgA antibodies (Islam et al., 1997; Phalipon et al., 2002; Pore et al., 2011). Sequential changes of humoral immune response within the antibody class are most important to determine immunogenicity of the antigens (Islam et al., 1995a; 1995b). Studies on humoral immunity in natural Shigella infections (Dinari et al., 1987; Witkowska et al., 1986) revealed that LPS, OMPs and IpBs play an important role in pathogenesis (Ashkenazi et al., 1999; Cohen et al., 1991; Perdomo et al., 1994) and subsequent protection
(Beckman et al., 1994; Czarny et al., 1992; Robbins and Schneerson, 1990). Immunomodulatory effect of OMPs on humoral immune response was shown by the number of Plaque-Forming Cells (PFCs) producing anti-Sheep Red Blood Cell (SRBC) antibodies (Czarny et al., 1992). Besides such envelope antigens, a number of Ip-related antigens represent major immune-stimulating moieties as dysenteric patients react with a strong and consistent Ipaspecific antibody response (Andrews et al., 1991; Oberhelman et al., 1991). Delayed and reduced adaptive humoral immune response was seen in children with shigellosis compared to adults (Raqib et al., 2002). However, earlier studies showed an antigenic relationship between major OMP and IpaB (Peterfi et al., 2007; Witkowska et al., 1986). A strong IgG-specific crossreactivity of human convalescent sera was also found between these antigens (Iankov et al., 2004; MartinezBecerra et al., 2012; Sieling et al., 1995). The kinetics of serum IgG responses against Shigella IpaB and IpaD have been studied after each course of immunization and was shown to have differential changes in mucosal IgA or IgG Antibody Secretory Cells (ASCs) suggesting a protective role of such secretory proteins (Andrews et al., 1991; Arranz et al., 1992; Camacho et al., 2011).

Importantly, the development of an effective candidate vaccine against infection requires critical analysis of the local and systemic immune response (Raqib et al., 2002). Heat killed or live attenuated $S$. flexneri 2a strain SC602 was used in a community based vaccine trial and $50 \%$ of the volunteers were found to have an increased IgA response to $S$. flexneri LPS (Katz et al., 2004; Mukhopadhaya et al., 2003; Robbins et al., 1992). The magnitude of the mucosal immune response to LPS was successfully elicited only in 19\% of the volunteers (Martinez-Becerra et al., 2012; Turbyfill et al., 2000). Anti-LPS and anti-Ipa antibodies as well as antibody-secreting cells were also evaluated in volunteers orally vaccinated with non-Shiga toxin producing $S$. dysenteriae (Hartman et al., 1994; Robbins et al., 1992; Samandari et al., 2000). Further, whole cell lysate-envelope fraction and OMPs were detected by the antisera against heat-killed $S$. flexneri 2 a (Hartman et al., 1994). Correlation between anti-LPS antibody titers and the level of protection to Opolysaccharide haptens of $S$. dysenteriae $1, S$. flexneri $2 \mathrm{a}$, or $S$. sonnei conjugated to various protein carriers have also been shown to possess parenteral, single-shot and low toxicity candidate vaccine (Harandi et al., 2003; Robbins et al., 1992; Robbins and Schneerson, 1990). These conjugated proteins induced mucosal humoral immunogenicity of the O-antigen against the homologous challenge (Ashkenazi et al., 1999). Such antibodies have also shown to be protected in invasion of Shigella into Coca-2 cells and may be curative (Chowers et al., 2007; Robbins et al., 1992). The high antibody $\mathrm{IgG}$ concentration induced by these conjugate vaccines in volunteers who did not develop shigellosis 
suggests that there is an association between serum antibody titer and protection.

\section{Cell-Mediated Immune Response to Shigella Surface Immunomodulators}

Current knowledge on host immune mechanism is limited to mucosal antibody response. Role of cellmediated immune responses in host defense system is yet to be understood. Therefore, factors involved in pathogenesis and patterns of the immunological responses during infection and its recovery must be considered in the development of a potent immunomodulator. Identification of immunogenic molecules either derived from a Shigella pathogen to modulate host T-cell functions (Beckman et al., 1994; Phalipon and Sansonetti, 2007) or detect some potential cellular and molecular targets against these antigenic molecules in order to acquire protection (Sieling et al., 1995; Sinha et al., 1992). Immunomodulatory effect of Shiga toxin released by Shigella have been shown to stimulate mononuclear cells including $\mathrm{CD}^{+}$or $\mathrm{CD} 8^{+} \mathrm{T}$ cells to proliferate (Samandari et al., 2000) and produce cytokine (Tesh et al., 1994). An increasing number of CD4 cells than that of CD8 cells in the lamina propria of Shigella infected patients with significant expression of Human Leukocyte Antigen (HLA)-DR revealed its significance in the induction of cell-mediated immune responses during acute shigellosis (Islam et al., 1995a; Raqib et al., 1994). Such cellular activation through Antigen Presenting Cells (APCs) may provide host defense against shigellosis elicited by vaccination (Bagchi and Sinha, 2004; Cohen et al., 1992). It is very well known that IpaB mediates apoptosis in macrophages induced by Shigella (Hilbi et al., 1998; Navarre and Zychlinsky, 2000; Perdomo et al., 1994) through IL-1 $\beta$-regulated caspase-1 activation (Hilbi et al., 1997). Thus Ipa's could be targeted as an immunomodulator since there was a robust mucosal antibody production as well as T cell-mediated immunity (Beckman et al., 1994; Cam et al., 1992; 1993; Oberhelman et al., 1991). Particularly, IpaB has been shown to have a protective role against lethal pulmonary infection by $S$. flexneri or $S$. sonnei. Thus these secretory Ipa antigens, IpaB and IpaD, have been suggested as potent immunomodulators which may provide crossprotection (Peterfi et al., 2007; Turbyfill et al., 2000). Synergistic effect of IpaB and IpaD has been shown to activate APCs and differentiate T-cells into Th1 (O'Hagan and Valiante, 2003; Robbins et al., 1992). Nevertheless, due to high cross-reactivity of these OMPs to Ipa's of the different groups of Gram-negative bacteria (Peterfi et al., 2007; Rabbi et al., 2008), these OMPs of Shigella and other genera of enterobacteriaceae have been shown to induce protection not only against homologous but also heterologous infection in a mouse model (Czarny et al., 1990). Although the OMPs are highly immunogenic and protective against lethal infection of Shigella (Adamus et al., 1980; Mulczyk et al., 1981), this results in immunosuppression of humoral as well as cellular responses (Mulczyk et al., 1987; Witkowska et al., 1986) in murine models. Hence, there is a need to develop cellular immunity of the host, which may be a critical factor in protection against shigellosis.

Immunity to Shigella infection is mainly characterized by sensitized T-cells (Islam et al., 1995a; 1996; Raqib et al., 1994) since there is increased inhibition of DTH (Mukhopadhaya et al., 2003; Mulczyk et al., 1987) and inflammatory cytokines (Raqib et al., 1995a; 1995b; 1995c; Way et al., 1998). Since protective immunity to shigellosis is delayed, patients may thus develop severe clinical complications (Azim et al., 1996; Raqib et al., 2002). Subcellular basis of Shigella destruction as well as immunological basis of T-cell suppression either in acute or chronic Shigella infection is not yet completely understood. However, studies on T-cell subsets suggest a biased induction of Th2 (Azim et al., 1996; Islam et al., 1995b). Therefore, lack of protective Th1 response during most of the experimental studies suggests a nature of T-cell suppression (Barman et al., 2011). Present scenario demands an alternative approach to our existing concept on cell-mediated immunity in shigellosis. Cellular immunity at the mucosal surface has been shown in the regulation of effector immune cell functions where $\mathrm{CD} 8^{+} \mathrm{T}$-cell response to live attenuated vaccines are thought to contribute significantly to crossprotection against various influenza strains (Sun et al., 2011). On the contrary, effector cell functions of CD8+ $\mathrm{T}$-cells have also failed to induce protection against shigellosis (Jehl et al., 2011). CD4 ${ }^{+} \mathrm{T}$ cells have also been shown in Shigella induced by outer membrane proteins (Bagchi and Sinha, 2004; Pore and Chakrabarti, 2013) through activation of either classical Toll-Like Receptor 2 (TLR2) or NLR innate signaling (Biswas et al., 2009; 2008; Phalipon and Sansonetti, 2007). Since TLRs activate cellular innate immunity, modulation in TLR2 signaling by porins may enhance $\mathrm{CD} 4^{+}$helper cell activity in order to acquire antibody response via APC and B-cell interaction (Biswas et al., 2009; 2008). However, activation of these helper cells together with CD25 enhances Interleukin-2 (IL-2) and Macrophage Inhibitory Factors (MIF) release instead of Activating Factors (MAF) required for T-cell regulation during acute stage of Shigella infection (Bagchi and Sinha, 2004). The presence of HLA-DR antigen with $\mathrm{CD}^{+}$helper T-cells in the gut mucosa of acute patients (Raqib et al., 1994) as well as T-cell restricted MHCclass II responses to major antigenic Shigella OMPs in immunized mice (Bagchi and Sinha, 2004; Pore and Chakrabarti, 2013) suggests a significant role of these helper T-cells in protection through activation of APCs. Furthermore, increased proliferation of $\mathrm{CD}^{+}$T-cells together with IL-2 in such immunized mice following infection was due to selective $\mathrm{CD}^{+} \mathrm{T}$-cell apoptosis by caspases-1 and IL-18 (Bagchi et al., 2010a). Overall, study suggested that recruitment of specific memory 
Th1-cells and their activation during Shigella infection following immunization may play a crucial role in the mitigation of the disease.

\section{Patterns Recognition Receptors (PRRs)- Specific Immunomodulation During Shigella Infection}

PRRs are not only specific to pathogen associated molecular patterns but also linked with DamageAssociated Molecular Patterns (DAMPs) induced by ceramides (synthesized due to bacterial toxins or surface components). These PRRs are critical regulators of innate immune system and are present on almost every cell type including APCs and M-cells. Bacterial outer membrane components such as Bacterial Lipoproteins (BLPs) or LPS are recognized by these PRRs such as TLR4 (Takeuchi et al., 2000). BLPs are characterized by a unique N-terminal lipo-amino acid also known to engage TLRs (Takeuchi et al., 2000). Since BLP is produced by all bacteria, it has important implications in immune system specific to pathogens thus making it a novel immunomodulator for therapeutic consideration. Immunomodulation of TLRs due to these bacterial outer membrane or secretory components have been studied in different in vitro conditions (Alurkar and Kamat, 1997; Wetzler et al., 1996) and has been shown to be involved in bacterial translocation leading to the activation of classical inflammatory responses through Nod-Like Receptors (NLR) innate signaling (Aliprantis et al., 2001; Phalipon and Sansonetti, 2007). Development of an effective immunomodulator using LPS as an adjuvant might trigger innate signaling via TLRs (Aliprantis et al., 2001; Alurkar and Kamat, 1997; Gribar et al., 2008). Recently, it has been reported that TLR activation is dependent on the number of acylated groups present in lipid A (Gribar et al., 2008; Rallabhandi et al., 2008). S. flexneri 2a elicited comparatively weaker TLR4-mediated innate immune response than $E$. coli LPS due to penta-acylated group of lipid A (Rallabhandi et al., 2008). Hence it is suggested that Shigella LPS-induced apoptosis is dependent on TLR2 (Aliprantis et al., 2001; 2000; Alurkar and Kamat, 1997; Rallabhandi et al., 2008), whereas it is independent on TLR4 (Aliprantis et al., 2001; Kaminski and Oaks, 2009; Ray and Biswas, 2005; Suzuki et al., 2005) through activation of IL-1 $\beta$ and IL-8 (Aliprantis et al., 2000; Toussi et al., 2012). On the other hand, porins of Shigella have been shown to activate TLR2 or TLR6 and modulate B-cell functions to maintain mucosal humoral response by $\mathrm{CD}^{+} \mathrm{T}$ cells (Ray et al., 2004). Such TLR adjuvant had induced B2-cells to produce $\operatorname{IgM}$ and $\mathrm{IgG}$ 2a (Ray and Biswas, 2005; Ray et al., 2003) and develop $\mathrm{CD}^{+} \mathrm{T}$-cell memory response (Biswas et al., 2009). Activation of TLR2 and TLR6 innate signaling promotes adaptive signaling via activation of CD80-CD86 (Ray et al., 2003; 2004) following effector T-cell functions (Aliprantis et al., 2001; Ray et al., 2004). These studies suggest that modulation of TLR or NLR innate signaling in adaptive response may last longer in the maintenance of cellular homeostasis in order to achieve protection against shigellosis (Phalipon and Sansonetti, 2007; Pore and Chakrabarti, 2013). These novel findings further provided drive for developing new candidate vaccines against mucosal pathogens that target TLRs.

\section{CyRs-Mediated Immunomodulation During Shigellosis}

Protective immune cell responses to the infection are provided through antigen specific signals in which cytokines and co-stimulatory molecules play an important role in the development of immunity (Chakrabarti and Sinha, 1997; Chowers et al., 2007; Le-Barillec et al., 2005; Raqib et al., 1994). During shigellosis, many inflammatory reactions are triggered by a wide range of cytokines mediated by innate immune system (Cohen et al., 1992; Raqib et al., 1995a). Inflammatory cytokines such as IL- 1 , IL-3, IL- 4 , IFN- $\gamma$, TGF- $\beta$ and TNF- $\alpha$ etc. have been identified during acute Shigella infection (Bagchi et al., 2010b; Raqib et al., 1995a) and have been shown to increase at the convalescent stage (Raqib et al., 1995b; 1995c). In vivo and in vitro studies have shown IFN- $\gamma$ induced innate resistance to primary Shigella infection (Cohen et al., 1991; Way et al., 1998). However, the path for a selective response is undefined which is possible only when the responses are being acquired through related antigens. Cytokines and their receptors may possibly gain an access in search of a selective pathway by generating adaptive immune responses. While their role in host defense mechanism are not well defined, it is known that the primary cytokines like MIF and MAF are released from the macrophages and are essential for the activation of classII antigens with T-cell (Bagchi and Sinha, 2004). During T-cell activation, pro- and anti-inflammatory cytokines such as IL-2, IL-4, IFN- $\gamma$ and IL-10 are released (Azim et al., 1996; Bagchi and Sinha, 2004; Islam et al., 1995a; Raqib et al., 1994) - this might help in CyRs activation resulting in memory T-cell activation and differentiation. Earlier, the concentration of IL-2 induced by a major OMP was determined in natural infection (Chakrabarti and Sinha, 1997). Elevation in IL2 and IFN- $\gamma$ levels in mice immunized with major OMPs suggested that $\mathrm{T}$-cell activation was induced to recall its memory against the antigen (Bagchi and Sinha, 2004; Herman et al., 1991; Toussi et al., 2012). It has been shown that IFN- $\gamma$ production not only by macrophages but also by T-cells may be considered as a surrogate biomarker for mucosal disease (Samandari et al., 2000; Witkowska et al., 1986) suggesting a role in cellular immunity against Shigella infection. Synthesis of IFN- $\gamma$ by T-cells appeared to increase when IpaB was administered alone (Cohen et al., 1991; Witkowska et al., 1986) or together with IpaD, reflecting a robust cellmediated immunity (Le-Barillec et al., 2005; 
Samandari et al., 2000). However, deficiency of IFN- $\gamma$ may aggravate the disease progression as there has been an increase in the number of intracellular Shigella further suggesting that IFN- $\gamma$ helps in controlling the infection (Way et al., 1998). Thus activation of IFN- $\gamma$ production by targeting its receptors may suppress the effect of primary inflammatory response due to generation of MIF by stimulated macrophages (Bagchi and Sinha, 2004). Thus, modulation in CyRs on the cell surface may be a better approach to alleviate inflammatory responses to antigens. In the presence of anti-IFN- $\gamma$ antibody, killed Shigella bacteria induced elevated IL-2 and IFN- $\gamma$ at the early stage of infection, but at the later stage, these IFN- $\gamma$ levels were diminished (Sinha and Bagchi, 2005). Data suggests that increased level of IFN- $\gamma$ production during acute phase may facilitate the up-regulation of antigen processing by means of generating high levels of oxygen free radicals. At the later stage, it was assumed that processed antigens are presented by APCs to T-cell through MHC-class II molecules and release protective cytokines (Bagchi and Sinha, 2004; Sinha and Bagchi, 2005; Witkowska et al., 1986). Therefore, immunomodulation of such targeted CyRs may represent one facet of cellular immunitythat could be important in resistance to Shigella organisms.

\section{TCR Ligand-Specific Immunomodulation Against Shigella Infection}

Immunosuppression in shigellosis is mediated by intra-epithelial memory T-cells. Immunosuppressive mode of Shigella infection is due to poor early activation or lack of these antigen-reactive T-cells. Regulatory activities of these memory T-cells at the mucosal site is still not clear. There have been several reports on polyclonal T-cell activators like anti-CD1, anti-CD2, anti-CD3 and anti-IL-2 which are often used either to induce lymphoid cell proliferation or cytokine secretion (Moreno-Lafont et al., 2003; Nguyen et al., 1995; Sieling et al., 1995; Sinha and Bagchi, 2004). Anti-CD3 (TCR ligand) identified on T-cell subsets has been not only known to activate and induce memory T-cell but also shown to promote the synthesis of new cytokines (Sinha and Bagchi, 2004). It is also known that activated memory T-cells play an important role in mediating antigen specific response to bacteria. In addition, memory T-cells have been shown to determine IFN- $\gamma$ levels which strongly reflects their role in regulation of Th1 cytokines (Bagchi et al., 2010a; Sinha and Bagchi, 2004). Activation of TCRs by TCR ligand or OX40 ligand (a co-stimulator of Th1-cell) contributes to maintain effector T-cell function as well as to develop memory against antigen-specific stimulation (Bagchi et al., 2010a; Maxwell et al., 2000) via activation of anti-apoptotic Bcl-xl expression of Bcl-2 family proteins (Rogers et al., 2001). The TCR ligand, anti-CD3 antibody, was also found to trigger effective T-cell function against Shigella antigens and elicit adaptive immune response against shigellosis (Bagchi et al., 2010a). This suggests that TCRs might ameliorate the property of Shigella surface antigens as a potential immuno-dominant candidate.

Shigella alone may not explain their immune stimulating moieties due to poor activation of reactive $\mathrm{T}$ cells. During the course of infection, therefore, regulatory activities of the memory T-cells are needed to be considered to activate biased signals for antigenspecific receptors. During maturation and activation of TCR, IL-2R expressed on T-cell is required for IL-2 growth factors via co-receptor molecule such as CD28 leading to IL-2 and IFN- $\gamma$ secretion towards the cellular target. In the presence of co-stimulatory signals, TCR ligands may also activate memory T-cells via TCR activation (Bagchi and Sinha, 2005; Sinha and Bagchi, 2004). Conversely, in the absence of these signals, TCR cells develop tolerance (Barrett et al., 1993). TCR activation by anti-CD3 ligand stimulation in murine Tcells has been shown to induce IL-2 secretory T-cells and requires co-stimulatory signals for further activation and proliferation of memory T-regulatory cells (Moreno-Lafont et al., 2003; Sinha and Bagchi, 2004). T-cell activation up-regulates protein kinase-Cmediated phosphorylation in $\mathrm{CD}^{+}$T-cells which enhances IL-2 production, lipid peroxidation as well as formation of reactive oxygen species (ROS) (Bagchi and Sinha, 2005; Sinha and Bagchi, 2004). Increased production of IL-2 enhances its receptor (CD25) activation on macrophages (Sinha and Bagchi, 2004). The ligand-induced TCR activation might suppress the naïve or memory $\mathrm{CD} 8^{+} \mathrm{T}$-cells resulting in $\mathrm{CD} 4^{+} \mathrm{T}$-cell selection (Bagchi et al., 2010b). On the other hand, TCR ligand- induced $\mathrm{T}$ helper cell activity was shown to produce IgG and or IgM by B-cells (Bagchi et al., 2010b). Data suggests that antibody can provide B- cell mediated adaptive immunity. Adaptive immunity to intracellular pathogens is mediated by sensitized T-cells in which both $\mathrm{CD}^{+}$and $\mathrm{CD} 8^{+} \mathrm{T}$ cells contribute to the protection against subsequent challenges (Bagchi et al., 2010a; Phalipon and Sansonetti, 2007) via Phosphoinositide 3-Kinase (PI3K) pathway (Bagchi and Sinha, 2005). Thus, anti-CD3 antibody would be an immuno-stimulatory molecule to induce adaptive immune responses through TCR activation. Such ligandinduced T-cell modulation may efficiently promote the ability of the used (specific) antigen in achieving immunity to shigellosis.

\section{Conclusion}

The antibody response as an approach to evaluate the immune mechanism is responsible for immunity induced in vaccinated animals. The antigenicity to immunomodulators either from Shigella surface antigens or other adjuvants delivered as a carrier molecule would primarily depend on the strength and amount of cellspecific signal generated against Shigella infection. 


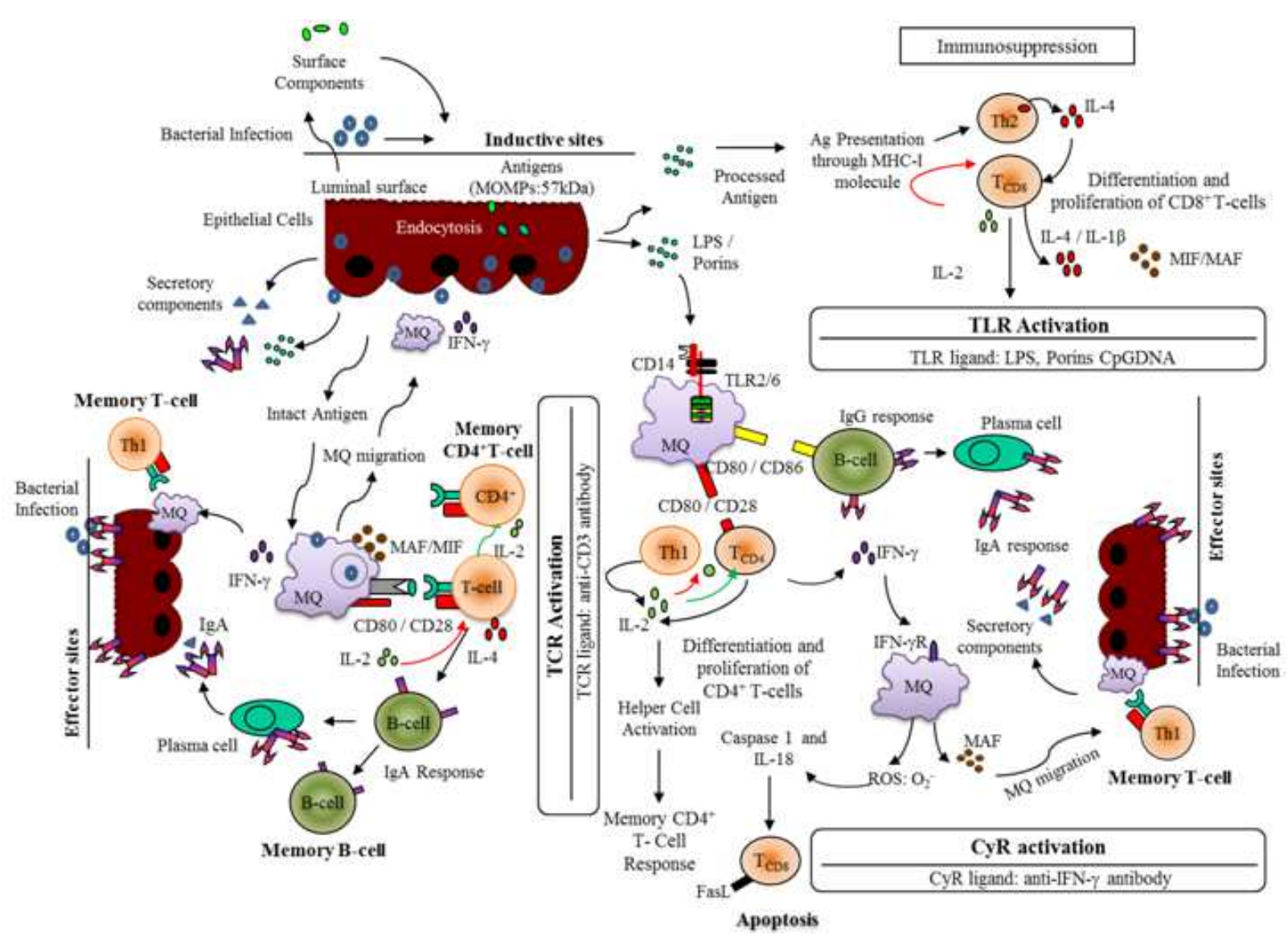

Fig. 1. Schematic diagram represents the cellular basis of receptor immune-modulation due to Shigella surface immunomodulators at the mucosal lining via activation of Pattern Recognition Receptors (PRRs) such as Toll-Like Receptors (TLRs), T-Cell Receptors (TCRs) and Cytokine Receptors (CyRs). Antigen specific cellular immune response at the mucosal sites, where Shigella Major Outer Membrane Proteins (MOMPs) such as $57 \mathrm{kDa}$ antigen are exposed to the inductive sites to either trigger Ig secretory components, or help in phagocytosis by Macrophage (MQ). Antigens are now processed and presented to T-cell through Major Histocompatibility (MHC) class I or II molecules presents on MQ. During this process, Interferon (IFN)- $\gamma$ facilitates the upregulation of antigen processing by means of generating high level of oxygen free radicals such as superoxide anions $\left(\mathrm{O}_{2}{ }^{-}\right)$and MQ Activation Factors (MAF) instead of MQ Inhibition Factors (MIF) (Bagchi and Sinha, 2004). These primary cytokine, MAF helps MQs to migrate at the infection sites by inhibiting MIF released at very initial hours. During this process, T-cells releases Interleukin (IL)-2 or IL-4, helps in cell proliferation, differentiation and growth in autocrine (red line) or paracrine (green line) fashion. The fate of the $\mathrm{T}$ cell population, $\mathrm{CD} 4^{+}$or $\mathrm{CD} 8^{+} \mathrm{T}$-cell selection is depending on the strength of primary signal lineage therefore generated helper or suppressor cell activity promoted by either IL-2 or IL-4 respectively. Panel A: IL-2 promoted the helper T-cell activity through MHC-II molecule while IL-4 promoted suppressor T-cell (CD8 ${ }^{+}$) through MHC-I molecule and cause immunosuppression. Panel B: Adjuvants, such as porins activates innate signaling via expression of TLR2 and TLR6 on the MQs and interact with $\mathrm{CD}^{+}$specific T-cell (Biswas et al., 2009; Biswas et al., 2008), which later interact with activated Bcells through secondary signal (CD80/CD86) (Ray et al., 2003) as a result of which confers mucosal immunity by production of immunoglobulin (Ig) G and IgA (Toussi et al., 2012) specific for antigen at the effector site. Panel C: Cytokines such as IFN- $\gamma$ may also play an important role in shigellosis as there was an overproduction of these IFN- $\gamma$ during the course of the disease which might not be beneficial to substantiate the progression of the disease (Raqib et al., 1995; Raqib et al., 1995). Thus modulation in CyR by using anti-IFN- $\gamma$ antibody to internalize its effect might be helpful to protect from its overproduction (Moreno-Lafont et al., 2003). Panel D: Immunomodulation of TCR upon its ligand (anti-CD3 antibody) stimulation activates secondary signals for CD80/CD28 (Bagchi and Sinha, 2005; Bagchi et al., 2010), but in absence of these signals, TCR cells develop tolerance (Barrett et al., 1993). TCR ligand further stimulates and promotes proliferation of IL-2 specific memory Tcells (Bagchi et al., 2010; Nguyen et al., 1995). T-cell ligands are activated when CD4 ${ }^{+}$T either interacts with their receptors on B-cell to generate antigen specific signals for the production $\operatorname{IgG} 2 \mathrm{a} / 2 \mathrm{~b}$ antibody (Maxwell et al., 2000) to neutralize the deleterious effects at the effector site or interacts with macrophage and increases $\mathrm{CD}^{+} \mathrm{T}$-cell apoptosis due to caspase-1 activation and IL-18 via increase oxidative stress and MIF (Bagchi and Sinha, 2004; Bagchi et al., 2010). Once memory $\mathrm{CD} 4{ }^{+} \mathrm{T}$-cells are activated by repeated exposure of bacterial antigens either in natural or induced using candidates, leads to development of adaptive immunity by means of generating biased signal 
Cellular basis of receptor immune-modulation for mucosal infection has been described schematically (Fig. 1), where immunomodulation of host cell receptors such as TLRs, TCRs, or Cytokine Receptors (CyRs) to Shigella-antigen specific signals in order to target vaccines against mucosal infections has been shown. TLRs could be a novel target transport pathway through mucosal cell lining. The focus of our present review is to emphasize the most potential immunomodulators used alone or in combination with adjuvants such as TLR, CyR and TCR ligands, that may confirm high antigenicity following natural and experimental shigellosis. The dearth of mucosal ligands or adjuvants and the mode of its delivery have led researchers to learn about vaccine approaches that only target protective immuno-dominant antigens specific to cellular receptors such as PRRs, CyRs and TCRs. This approach may enhance the immunogenicity of an antigen to develop precise and biased immune response by switching innate response to antigen-specific adaptive immune response to ensure long lasting protection against subsequent infection. Major antigenic fraction of OMPs identified and elicited an antibody response during natural infection. Some of our studies suggest that the TCR ligand, anti-CD3, used as an immunomodulator supplemented with Shigella antigen, may develop memory in Cell-Mediated Immune (CMI)-restored patients and help in gaining antigen specific signals for Th1 in Th0 subsets. Vaccines targeting TLRs, CyRs and TCRs may possibly lead to generation of effective immune cell responses. However, their physiological function to influence helper T-cells is yet to be further ascertained in shigellosis. Indeed, there is a need of an immunomodulator that can promote strikingly biased Th1-mediated antibody response in a vaccine formulation against shigellosis.

\section{Acknowledgement}

The authors thank the National Institute of Cholera and Enteric Diseases (NICED), India where AKB, DKH and DRS performed research on Shigella. RAB and FJ were previously affiliated with The Maharaja Sayajirao University of Baroda and Stamford University respectively. RAB and FJ are currently recipients of graduate studentships from Canadian Institutes of Health Research (CIHR) and Research Manitoba respectively.

\section{Author's Contributions}

Original concept and design: AKB; Material and literature search/collection: AKB, RAB, DKH, FJ, PHP, DRS; Manuscript writing: AKB, RAB, DKH, FJ, PHP, DRS; Final editing: AKB RAB, DKH, FJ, DRS, Schematic figure: RAB, FJ, AKB.

\section{Ethics}

This article is original and contains unpublished material. The corresponding author confirms that all of the other authors have read and approved the manuscript and no ethical issues involved

\section{References}

Acha-Orbea, H.M., 1993. Roles of superantigens in microbial infections? Res. Immunol., 144: 198-201. PMID: 8235042

Adamus, G., M. Mulczyk, D. Witkowska and E. Romanowska, 1980. Protection against keratoconjunctivitis shigellosa induced by immunization with outer membrane proteins of Shigella spp. Infect. Immunol., 30: 321-324. PMID: 7002794

Aliprantis, A.O., D.S. Weiss, J.D. Radolf and A. Zychlinsky, 2001. Release of toll-like receptor-2activating bacterial lipoproteins in Shigella flexneri culture supernatants. Infect. Immunol., 69: 6248-6255. DOI: 10.1128/IAI.69.10.6248-6255.2001

Aliprantis, A.O., R.B. Yang, D.S. Weiss, P. Godowski and A. Zychlinsky, 2000. The apoptotic signaling pathway activated by toll-like receptor-2. EMBO J., 19: 3325-3336. DOI: 10.1093/emboj/19.13.3325

Alurkar, V. and R. Kamat, 1997. Immunomodulatory properties of porins of some members of the family Enterobacteriaceae. Infect. Immunol., 65: 2382-2388. PMID: 9169778

Andrews, G.P., A.E. Hromockyj, C. Coker and A.T. Maurelli, 1991. Two novel virulence loci, mxiA and $\mathrm{mxiB}$, in Shigella flexneri 2a facilitate excretion of invasion plasmid antigens. Infect. Immunol., 59: 1997-2005. PMID: 2037361

Anh, N.T., P.D. Cam and A. Dalsgaard, 2001. Antimicrobial resistance of Shigella spp isolated from diarrheal patients between 1989 and 1998 in Vietnam. Southeast Asian J. Trop. Med. Public Health, 32: 856-62. PMID: 12041563

Arranz, E., S. O'mahony, J.R. Barton and A. Ferguson, 1992. Immunosenescence and mucosal immunity: Significant effects of old age on secretory IgA concentrations and intraepithelial lymphocyte counts. Gut, 33: 882-886. PMID: 1644326

Ashkenazi, S., J.H. Passwell, E. Harlev, D. Miron and R. Dagan et al., 1999. Safety and immunogenicity of Shigella sonnei and Shigella flexneri 2a O-specific polysaccharide conjugates in children. J. Infect. Dis., 179: 1565-1568. DOI: 10.1086/314759

Azim, T., M.S. Sarker, J. Hamadani, N. Khanum and R.C. Halder et al., 1996. Alterations in lymphocyte phenotype and function in children with shigellosis who develop complications. Clin. Diagn. Lab Immunol., 3: 191-196. PMID: 8991634 
Bagchi, A.K. and A.K. Sinha, 2005. Phosphotidylinositol-3 kinase-mediated signals in mice immunized with the $57 \mathrm{kDa}$ major antigenic outer-membrane protein of Shigella dysenteriae type 1. J. Med. Microbiol., 54: 631-637. DOI: $10.1099 / \mathrm{jmm} .0 .46014-0$

Bagchi, A.K. and A.K. Sinha, 2004. Role of $57 \mathrm{kDa}$ major antigenic component of Shigella dysenteriae outer membrane proteins in induction of major histocompatibility complex II-restricted T-cell response. Arch Med. Res., 35: 427-434.

DOI: 10.1016/j.arcmed.2004.05.007

Bagchi, A.K., A.K. Sinha, R. Adhikari, P. Maiti and Mukherjee et al., 2010a. Selective deletion of CD8(+) cells upregulated by caspases-1 via IL-18 in mice immunized with major outer membrane protein of Shigella dysenteriae 1 following infection. J. Clin. Immunol., 30: 408-418. DOI: $10.1007 / \mathrm{s} 10875-009-9359-8$

Bagchi, A.K., A.K. Sinha, R. Adhikari and J. Mukherjee, 2010b. Adaptive immune responses during Shigella dysenteriae type 1 infection: an in vitro stimulation with $57 \mathrm{kDa}$ major antigenic OMP in the presence of anti-CD3 antibody. Mol. Cell Biochem., 338: 1-10. DOI: $10.1007 / \mathrm{s} 11010-009-0314-\mathrm{Z}$

Barman, S., R. Kumar, G. Chowdhury, D. Rani Saha and T. Wajima et al., 2011. Live non-invasive Shigella dysenteriae 1 strain induces homologous protective immunity in a guinea pig colitis model. Microbiol. Immunol., 55: 683-693.

DOI: $10.1111 / \mathrm{j} .1348-0421.2011 .00371 . x$

Barrett, T.A., Y. Tatsumi and J.A. Bluestone, 1993. Tolerance of $\mathrm{T}$ cell receptor gamma/delta cells in the intestine. J. Exp. Med., 177: 1755-1762. PMID: 8098732

Beckman, E.M., S.A. Porcelli, C.T. Morita, S.M. Behar and S.T. Furlong et al., 1994. Recognition of a lipid antigen by CD1-restricted alpha beta $+\mathrm{T}$ cells. Nature, 372: 691-694. DOI: 10.1038/372691a0

Biswas, A., P. Banerjee and T. Biswas, 2009. Porin of Shigella dysenteriae directly promotes toll-like receptor 2-mediated CD4+ $\mathrm{T}$ cell survival and effector function. Mol. Immunol., 46: 3076-3085. DOI: 10.1016/j.molimm.2009.06.006

Biswas, A., P. Banerjee and T. Biswas, 2008. Priming of CD4+ T cells with porin of Shigella dysenteriae activates the cells toward type 1 polarization. Int. Immunol., 20: 81-88. DOI: 10.1093/intimm/dxm122

Borisova, E.V., 1999. The role of the structural components of bacterial lipopolysaccharide in its inductive immunosuppressive activity. Mikrobiol. Z, 61: 36-41. PMID: 10707531

Buchanan, T.A. and W.A. Pearce, 1979. Pathogenic aspects of outer membrane components of gramnegative bacteria. Bacterial Outer Membranes, Biogenesis and function.
Cam, P.D., R. Achi, A.A. Lindberg and T. Pal, 1992. Antibodies against invasion plasmid coded antigens of shigellae in human colostrum and milk. Acta Microbiol. Hung., 39: 263-270. PMID: 1343940

Cam, P.D., T. Pal and A.A. Lindberg, 1993. Immune response against lipopolysaccharide and invasion plasmid-coded antigens of shigellae in Vietnamese and Swedish dysenteric patients. J. Clin. Microbiol., 31: 454-457. PMID: 8432838

Camacho, A.I., J. De Souza, S. Sanchez-Gomez, M. PardoRos and J. Irache et al., 2011. Mucosal immunization with Shigella flexneri outer membrane vesicles induced protection in mice. Vaccine, 29: 8222-8229. DOI: $10.1016 /$ j.vaccine.2011.08.121

CDC, 2015. National enteric disease surveillance: Shigella Annual Report, 2012. CDC.

CDCR, 2015. Multidrug-resistant shigellosis spreading in the United States. CDC Report.

Chakrabarti, S. and A.K. Sinha, 1994. A major antigenic outer membrane protein of Shigella dysenteriae 1: Role in adhesion to cultured mammalian cells. Med. Sci. Res., 22: 835-36.

Chakrabarti, S. and A.K. Sinha, 1997. Release of interleukin-2 induced by a major antigenic outer membrane protein of Shigella dysenteriae type 1 in natural infection. Microbios, 92: 123-132. PMID: 9589610

Chowers, Y., J. Kirschner, N. Keller, I. Barshack and S. Bar-Meir et al., 2007. O-specific [corrected] polysaccharide conjugate vaccine-induced [corrected] antibodies prevent invasion of Shigella into Caco-2 cells and may be curative. Proc. Nat. Acad. Sci. USA, 104: 2396-2401. DOI: 10.1073/pnas.0610833104

Cohen, D., M.S. Green, C. Block, T. Rouach and I. Ofek, 1988. Serum antibodies to lipopolysaccharide and natural immunity to shigellosis in an Israeli military population. J. Infect. Dis., 157: 1068-1071. PMID: 3283258

Cohen, D., M.S. Green, C. Block, R. Slepon and Y. Lerman, 1992. Natural immunity to shigellosis in two groups with different previous risks of exposure to Shigella is only partly expressed by serum antibodies to lipopolysaccharide. J. Infect. Dis., 165: 785-787. PMID: 1552217

Cohen, D., M.S. Green, C. Block, R. Slepon and I. Ofek, 1991. Prospective study of the association between serum antibodies to lipopolysaccharide $\mathrm{O}$ antigen and the attack rate of shigellosis. J. Clin. Microbiol., 29: 386-389. PMID: 1706731

Czarny, A., D. Witkowska and M. Mulczyk, 1992. Effect of outer membrane proteins from Shigella on humoral immunity induced in mice by SRBC. Arch. Immunol. Ther. Exp., 40: 129-134. PMID: 1299171 
Czarny, A., D. Witkowska and M. Mulczyk, 1990. Studies on nonspecific protection induced with OMP of Shigella flexneri and other genera of Enterobacteriaceae. Arch. Immunol. Ther. Exp., 38: 353-357. PMID: 2130800

Daniel, S.M. and J.B. Lawrence, 2003. Management and treatment of infectious diarrhea in the elderly. Clin. Geriatr.

D'hauteville, H., S. Khan, D.J. Maskell, A. Kussak and A. Weintraub et al., 2002. Two msbB genes encoding maximal acylation of lipid A are required for invasive Shigella flexneri to mediate inflammatory rupture and destruction of the intestinal epithelium. J. Immunol., 168: 5240-5251. PMID: 11994481

Dhodapkar, R., S.N. Acharya, B.N. Harish and S.C. Parijam 2008. Shigellosis in ponducherry. Ind. J. Med. Res., 127: 621-2.

Doyle, M.E., 2014. White paper: Public health impact of multi-drug resistant pathogens. Food Research Institute UW-Madison Report.

Doyle, M., G. Loneragan, H. Scott and R. Singer, 2013. Antimicrobial resistance: Challenges and perspectives. Comp. Rev. Food Sci. Food Safety, 12: 234-48. DOI: 10.1111/1541-4337.12008

Dinari, G., T.L. Hale, S.W. Austin and S.B. Formal, 1987. Local and systemic antibody responses to Shigella infection in rhesus monkeys. J. Infect. Dis., 155: 1065-1069. PMID: 3549918

DuPont, H.L., 1990. Shigella species (Bacillary Dysentery). In: Principles and Practice of Infectious Disease, Mandell, G.L., R.G. Douglas, Jr. and J.E. Bannett (Eds.), pp: 1716-1722.

DuPont, H.L., M.M. Levine, R.B. Hornick and S.B. Formal, 1989. Inoculum size in shigellosis and implications for expected mode of transmission. J. Infect. Dis., 159: 1126-1128. PMID: 2656880

Ferreccio, C., V. Prado, A. Ojeda, M. Cayyazo and P. Abrego et al., 1991. Epidemiologic patterns of acute diarrhea and endemic Shigella infections in children in a poor periurban setting in Santiago, Chile. Am. J. Epidemiol., 134: 614-627. PMID: 1951266

Gribar, S.C., W.M. Richardson, C.P. Sodhi and D.J. Hackam, 2008. No longer an innocent bystander: Epithelial toll-like receptor signaling in the development of mucosal inflammation. Mol. Med., 14: 645-659. DOI: 10.2119/2008-00035.Gribar

Harandi, A.M., J. Sanchez, K. Eriksson and J. Holmgren, 2003. Recent developments in mucosal immunomodulatory adjuvants. Curr. Opin. Investig. Drugs, 4: 156-161. PMID: 12669375

Hartman, A.B., L.L. Van De Verg, H.H. Collins, D.B. Tang and N.O. Bendiuk et al., 1994. Local immune response and protection in the guinea pig keratoconjunctivitis model following immunization with Shigella vaccines. Infect. Immunol., 62: 412-420. PMID: 7507892
Hens, D.K., S.K. Niyogi and R. Kumar, 2005. Epidemic strain Shigella dysenteriae type 1 Dt66 encodes several drug resistances by chromosome. Arch. Med. Res., 36: 399-403.

DOI: $10.1016 /$ j.arcmed.2005.03.006

Herman, A., J.W. Kappler, P. Marrack and A.M. Pullen, 1991. Superantigens: Mechanism of T-cell stimulation and role in immune responses. Annu. Rev. Immunol., 9: 745-772.

DOI: 10.1146/annurev.iy.09.040191.003525

Hilbi, H., Y. Chen, K. Thirumalai and A. Zychlinsky, 1997. The interleukin 1beta-converting enzyme, caspase 1, is activated during Shigella flexneriinduced apoptosis in human monocyte-derived macrophages. Infect. Immunol., 65: 5165-5170. PMID: 9393811

Hilbi, H., J.E. Moss, D. Hersh, Y. Chen and J. Arondel et al., 1998. Shigella-induced apoptosis is dependent on caspase-1 which binds to IpaB. J. Biol. Chem., 273: 32895-32900. PMID: 9830039

Iankov, I.D., D.P. Petrov, I.V. Mladenov, I.H. Haralambieva and O.K. Kalev et al., 2004. Protective efficacy of IgA monoclonal antibodies to $\mathrm{O}$ and $\mathrm{H}$ antigens in a mouse model of intranasal challenge with Salmonella enterica serotype Enteritidis. Microbes Infect., 6: 901-910. DOI: 10.1016/j.micinf.2004.05.007

Ingersoll, M.A. and A. Zychlinsky, 2006. ShiA abrogates the innate T-cell response to Shigella flexneri infection. Infect. Immunol., 74: 2317-2327. DOI: 10.1128/IAI.74.4.2317-2327.2006

Islam, D., P.K. Bardhan, A.A. Lindberg and B. Christensson, 1995. Shigella infection induces cellular activation of $\mathrm{T}$ and $\mathrm{B}$ cells and distinct species-related changes in peripheral blood lymphocyte subsets during the course of the disease. Infect. Immunol., 63: 2941-2949. PMID: 7622216

Islam, D., B. Veress, P.K. Bardhan, A.A. Lindberg and B. Christensson, 1997. Quantitative assessment of $\mathrm{IgG}$ and IgA subclass producing cells in rectal mucosa during shigellosis. J. Clin. Pathol., 50: 513-520. PMID: 9378821

Islam, D., B. Wretlind, A.A. Lindberg and B. Christensson, 1996. Changes in the peripheral blood $\mathrm{T}$-Cell receptor $\mathrm{V}$ beta repertoire in vivo and in vitro during shigellosis. Infect Immun, 64:1391-1399. PMID: 8606106

Islam, D., Wretlind, B., Ryd, M., Lindberg, A. A. and Christensson, B. 1995. Immunoglobulin subclass distribution and dynamics of Shigella-specific antibody responses in serum and stool samples in shigellosis. Infect. Immunol., 63: 2054-2061. PMID: 7729920 
Jehl, S.P., A.M. Doling, K.S. Giddings, A. Phalipon and P.J. Sansonetti et al., 2011. Antigen-specific CD8(+) $\mathrm{T}$ cells fail to respond to Shigella flexneri. Infect. Immunol., 79: 2021-2030. DOI: 10.1128/IAI.00939-10

Kaminski, R.W. and E.V. Oaks, 2009. Inactivated and subunit vaccines to prevent shigellosis. Expert Rev. Vaccines, 8: 1693-1704. DOI: $10.1586 /$ erv.09.127

Katz, D.E., T.S. Coster, M.K. Wolf, F.C. Trespalacios and D. Cohen et al., 2004. Two studies evaluating the safety and immunogenicity of a live, attenuated Shigella flexneri 2a vaccine (SC602) and excretion of vaccine organisms in North American volunteers. Infect. Immunol., 72: 923-930. PMID: 14742537

Keusch, G.T., 1986. Shigella. In: Infectious Diarrhoea, Gorbach, S.L. (Ed.), Blackwell Scientific Publication, Boston, Oxford, London, Edinburgh, Melbourne, Palo Alto, pp: 31-50.

Keusch, G.T., M.L. Bennish and D. Acheson, 1988. Shigella. In: Invasive Enteropathies with a Special Emphasis on Shigellosis, Epidemiology, Biological and Clinical Consideration, ADDR Workshop on Invasive Diarrhoea, Bangkok, Thailand, pp: 1- 22.

Khan, W., C. Seas, U. Dhar, M.A. Salam and M.L. Bennish, 1997. Treatment of shigellosis: V. Comparison of azithromycin and ciprofloxacin. A double-blind, randomized, controlled trial. Ann. Intern. Med., 126: 697-703. PMID: 9139555

Kotloff, K.L., J.P. Winickoff, B. Ivanoff, J.D. Clemens and D.L. Swerdlow et al., 1999. Global burden of Shigella infections: implications for vaccine development and implementation of control strategies. Bull. WHO, 77: 651-666. PMID: 10516787

Kuehn, M.J. and N.C. Kesty, 2005. Bacterial outer membrane vesicles and the host-pathogen interaction. Genes Dev., 19: 2645-2655.

DOI: $10.1101 / \mathrm{gad} .1299905$

Le-Barillec, K., J.G. Magalhaes, E. Corcuff, A. Thuizat and P.J. Sansonetti et al., 2005. Roles for T and NK cells in the innate immune response to Shigella flexneri. J. Immunol., 175: 1735-1740. PMID: 16034114

Lindberg, A.A. and T. Pal, 1993. Strategies for development of potential candidate Shigella vaccine. Vaccine, 11: 168-179. PMID: 8438615

Mache, A., 2001. Antibiotic resistance and sero-groups of Shigella among paediatric out-patients in southwest Ethiopia. East Afr. Med. J., 78: 296-299. PMID: 12002106
Mamatha, B., B.R. Pusapati and C. Rituparn, 2007. Changing patterns of antimicrobial susceptibility of Shigella serotypes isolated from children with acute diarrhea in Manipal, South India, a 5 year study. Southeast Asian J. Trop. Med. Public Health, 38: 863-866. PMID: 18041303

Martinez-Becerra, F.J., J.M. Kissmann, J. Diaz-Mcnair, S.P. Choudhari and A.M. Quick et al., 2012. Broadly protective Shigella vaccine based on type III secretion apparatus proteins. Infect. Immunol., 80: 1222-1231. DOI: 10.1128/IAI.06174-11

Maxwell, J.R., A. Weinberg, R.A. Prell and A.T. Vella, 2000. Danger and OX40 receptor signaling synergize to enhance memory $\mathrm{T}$ cell survival by inhibiting peripheral deletion. J. Immunol., 164: 107-112. PMID: 10605000

Mitra, S., S. Barman, D. Nag, R. Sinha and D.R. Saha et al., 2012. Outer membrane vesicles of Shigella boydii type 4 induce passive immunity in neonatal mice. FEMS Immunol. Med. Microbiol., 66: 240-250. DOI: 10.1111/j.1574-695X.2012.01004.x

Moreno-Lafont, M.C., R. Lopez-Santiago, V. ParedesCervantes, A. Estrada-Aguilera and L. SantosArgumedo, 2003. Activation and proliferation of $\mathrm{T}$ lymphocyte subpopulations in patients with brucellosis. Arch. Med. Res., 34: 184-193. DOI: 10.1016/S0188-4409(03)00020-1

Morduchowicz, G., D. Huminer, Y. Siegman-Igra, M. Drucker and C.S. Block et al., 1987. Shigella bacteremia in adults. A report of five cases and review of the literature. Arch. Internal Med., 147: 2034-2037. PMID: 3314766

Mukhopadhaya, A., D. Mahalanabis, J. Khanam and M.K. Chakrabarti, 2003. Protective efficacy of oral immunization with heat-killed Shigella flexneri $2 \mathrm{a}$ in animal model: Study of cross protection, immune response and antigenic recognition. Vaccine, 21: 3043-3050. PMID: 12798648

Mulczyk, M., G. Adamus, D. Witkowska and E. Romanowska, 1981. Studies on virulence of Shigella flexneri. Protective effect of outer membrane proteins. Arch. Immunol. Ther. Exp., 29: 85-90. PMID: 7025793

Mulczyk, M., D. Witkowska and J. Mleczko, 1987. Hypersensitivity to Shigella outer membrane proteins in mice. Arch. Immunol. Ther. Exp., 35: 763-768. PMID: 2977277

Murphy, G.S., L. Bodhidatta, P. Echeverria, S. Tansuphaswadikul and C.W. Hoge et al., 1993. Ciprofloxacin and loperamide in the treatment of bacillary dysentery. Annals Internal Med., 118: 582-586. PMID: 8452323 
Navarre, W.W. and A. Zychlinsky, 2000. Pathogeninduced apoptosis of macrophages: A common end for different pathogenic strategies. Cell Microbioll., 2: 265-273. PMID: 11207583

Nguyen, D.D., L. Beck and H.L. Spiegelberg, 1995. Anti-CD3-induced anergy in cloned human Th0, Th1 and Th2 cells. Cell Immunol., 165: 153-157. DOI: $10.1006 /$ cimm.1995.1199

Oaks, E.V., T.L. Hale and S.B. Formal, 1986. Serum immune response to Shigella protein antigens in rhesus monkeys and humans infected with Shigella spp. Infect. Immunol., 53: 57-63. PMID: 3721580

O'hagan, D.T. and N.M. Valiante, 2003. Recent advances in the discovery and delivery of vaccine adjuvants. Nat. Rev. Drug Discov., 2: 727-735. DOI: $10.1038 /$ nrd1176

Oberhelman, R.A., D.J. Kopecko, E. Salazar-Lindo, E. Gotuzzo and J.M. Buysse et al., 1991. Prospective study of systemic and mucosal immune responses in dysenteric patients to specific Shigella invasion plasmid antigens and lipopolysaccharides. Infect. Immunol., 59: 2341-2350. PMID: 2050402

Oldfield, E.C. III. and M.R. Wallace, 2001. The role of antibiotics in the treatment of infectious diarrhea. Gastroenterol. Clin. North Am., 30: 817-835. PMID: 11586559

WHO, 2014. Antimicrobial Resistance: Global Report on Surveillance. 1st Edn., World Health Organization, ISBN-13: 9789241564748, pp: 257.

Passwell, J.H., S. Freier, R. Shor, N. Farzam and C. Block et al., 1995. Shigella lipopolysaccharide antibodies in pediatric populations. Pediatr. Infect. Dis. J., 14: 859-865. PMID: 8584312

Perdomo, O.J., J.M. Cavaillon, M. Huerre, H. Ohayon and P. Gounon et al., 1994. Acute inflammation causes epithelial invasion and mucosal destruction in experimental shigellosis. J. Exp. Med., 180: 1307-1319. PMID: 7931064

Peterfi, Z., I. Kustos, F. Kilar and B. Kocsis, 2007. Microfluidic chip analysis of outer membrane proteins responsible for serological cross-reaction between three Gram-negative bacteria: Proteus morganii O34, Escherichia coli $\mathrm{O} 111$ and Salmonella Adelaide O35. J. Chromatogr. A, 1155: 214-217. DOI: 10.1016/j.chroma.2007.02.093

Phalipon, A., A. Cardona, J.P. Kraehenbuhl, L. Edelman and P.J. Sansonetti et al., 2002. Secretory component: A new role in secretory IgA-mediated immune exclusion in vivo. Immunity, 17: 107-115. PMID: 12150896

Phalipon, A. and P.J. Sansonetti, 2007. Shigella's ways of manipulating the host intestinal innate and adaptive immune system: A tool box for survival? Immunol. Cell Biol., 85: 119-129.

DOI: $10.1038 /$ sj.icb7100025
Pore, D. and M.K. Chakrabarti, 2013. Outer membrane protein A (OmpA) from Shigella flexneri 2a: A promising subunit vaccine candidate. Vaccine, 31: 3644-3650. DOI: 10.1016/j.vaccine.2013.05.100

Pore, D., P. Chowdhury, N. Mahata, A. Pal and S. Yamasaki et al., 2009. Purification and characterization of an immunogenic outer membrane protein of Shigella flexneri $2 \mathrm{a}$. Vaccine, 27: 5855-5864.

DOI: $10.1016 /$ j.vaccine.2009.07.054

Pore, D., N. Mahata, A. Pal and M.K. Chakrabarti, 2011. Outer membrane protein A (OmpA) of Shigella flexneri $2 \mathrm{a}$, induces protective immune response in a mouse model. PLoS One, 6: e22663-e22663.

DOI: 10.1371/journal.pone.0022663

Rabbi, F., N. Sultana, T. Rahman, H.M. Al-Emran and M.N. Uddin et al., 2008. Analysis of immune responses and serological cross reactivities among Vibrio cholerae O1, Shigella flexneri $2 \mathrm{a}$ and Haemophilus influenzae b. Cell Mol. Immunol., 5: 393-396. DOI: $10.1038 / \mathrm{cmi} .2008 .49$

Rallabhandi, P., A. Awomoyi, K.E. Thomas, A. Phalipon and Y. Fujimoto et al., 2008. Differential activation of human TLR4 by Escherichia coli and Shigella flexneri 2a lipopolysaccharide: combined effects of lipid a acylation state and TLR4 polymorphisms on signaling. J. Immunol., 180: 1139-1147. PMID: 18178854

Raqib, R., A.A. Lindberg, L. Bjork, P.K. Bardhan and B. Wretlind et al., 1995a. Down-regulation of gamma interferon, tumor necrosis factor type I, interleukin 1 (IL-1) type I, IL-3, IL-4 and transforming growth factor beta type I receptors at the local site during the acute phase of Shigella infection. Infect. Immunol., 63: 3079-3087. PMID: 7622234

Raqib, R., A.A. Lindberg, B. Wretlind, P.K. Bardhan and U. Andersson et al., 1995b. Persistence of local cytokine production in shigellosis in acute and convalescent stages. Infect. Immunol., 63: 289-296. PMID: 7806368

Raqib, R., F. Qadri, P. Sarker, S.M. Mia and P.J. Sansonnetti et al., 2002. Delayed and reduced adaptive humoral immune responses in children with shigellosis compared with in adults. Scand J. Immunol., 55: 414-423. PMID: 11967124

Raqib, R., F.P. Reinholt, P.K. Bardhan, A. Karnell and A.A. Lindberg, 1994. Immunopathological patterns in the rectal mucosa of patients with shigellosis: Expression of HLA-DR antigens and T-lymphocyte subsets. APMIS, 102: 371-380. PMID: 8024739 
Raqib, R., B. Wretlind, J. Andersson and A.A. Lindberg, 1995c. Cytokine secretion in acute shigellosis is correlated to disease activity and directed more to stool than to plasma. J. Infect. Dis., 171: 376-384. PMID: 7531208

Ray, A. and T. Biswas, 2005. Porin of Shigella dysenteriae enhances Toll-like receptors 2 and 6 of mouse peritoneal B-2 cells and induces the expression of immunoglobulin $\mathrm{M}$, immunoglobulin $\mathrm{G} 2 \mathrm{a}$ and immunoglobulin $\mathrm{A}$. Immunology, 114: 94-100. DOI: $10.1111 / \mathrm{j} .1365-2567.2004 .02002 . \mathrm{x}$

Ray, A., N.S. Chatterjee, S.K. Bhattacharya and T. Biswas, 2003. Porin of Shigella dysenteriae enhances mRNA levels for Toll-like receptor 2 and MyD88, up-regulates CD80 of murine macrophage and induces the release of interleukin-12. FEMS Immunol. Med. Microbiol., 39: 213-219. PMID: 14642305

Ray, A., P. Karmakar and T. Biswas, 2004. Upregulation of CD80-CD86 and IgA on mouse peritoneal B-1 cells by porin of Shigella dysenteriae is Toll-like receptors 2 and 6 dependent. Mol. Immunol., 41: 1167-1175.

DOI: 10.1016/j.molimm.2004.06.007

Robbins, J.B., C. Chu and R. Schneerson, 1992. Hypothesis for vaccine development: protective immunity to enteric diseases caused by nontyphoidal salmonellae and shigellae may be conferred by serum IgG antibodies to the O-specific polysaccharide of their lipopolysaccharides. Clin. Infect. Dis., 15: 346-361. PMID: 1381621

Robbins, J.B. and R. Schneerson, 1990. Polysaccharideprotein conjugates: A new generation of vaccines. J. Infect. Dis., 161: 821-832. PMID: 2182727

Rogers, P.R., J. Song, I. Gramaglia, N. Killeen and M. Croft, 2001. OX40 promotes Bcl-xL and Bcl-2 expression and is essential for long-term survival of CD4 T cells. Immunity, 15: 445-455. PMID: 11567634

Roy, S. and T. Biswas, 1996. Murine splenocyte proliferation by porin of Shigella dysenteriae type 1 and inhibition of bacterial invasion of HeLa cell by anti-porin antibody. FEMS Microbiol. Lett., 141: 25-29. PMID: 8764507

Samandari, T., K.L. Kotloff, G.A. Losonsky, W.D. Picking and P.J. Sansonetti et al., 2000. Production of IFN-gamma and IL-10 to Shigella invasins by mononuclear cells from volunteers orally inoculated with a Shiga toxin-deleted Shigella dysenteriae type 1 strain. J. Immunol., 164: 2221-2232. PMID: 10657678

Sieling, P.A., D. Chatterjee, S.A. Porcelli, T.I. Prigozy and R.J. Mazzaccaro et al., 1995. CD1-restricted T cell recognition of microbial lipoglycan antigens. Science, 269: 227-230. PMID: 7542404
Sinha, A.K. and A.K. Bagchi, 2005. Cytokine release induced by killed bacteria associated with antiIFN-gamma antibody in Shigella infection. Cytokine, 31: 87-93. DOI: $10.1016 /$ j.cyto.2005.03.004

Sinha, A.K. and A.K. Bagchi, 2004. Role of anti-CD3 in modulation of Th1-type immune response in Shigella dysenteriae infection. J. Med. Microbiol., 53: 1075-1081. PMID: 15496383

Sinha, A.K., M.K. Chakraborti and S. Chakraborti, 1992. Gut mucosal lymphocyte subpopulations in the hostdefence of Shigella infected guinea-pigs. Immunol. Lett., 32: 65-68. PMID: 1500085

Sinha, A.K., S. Chakrabarti and M.K. Chakraborti, 1994. Delayed hypersensitivity in relation to host cellular immune response in Shigella infected mice. Immunol. Infect. Dis., 4: 149-152.

Srinivasa, H., M. Baijayanti and B.Y. Raksha, 2009. Magnitude of drug resistant shigellosis: A report from Bangalore. Ind. J. Med. Microbiol., 27: 358-360. PMID: 19736408

Sun, K., J. Ye, D.R. Perez and D.W. Metzger, 2011. Seasonal FluMist vaccination induces cross-reactive T cell immunity against H1N1 (2009) influenza and secondary bacterial infections. J. Immunol., 186: 987-993. DOI: 10.4049/jimmunol.1002664

Suzuki, T., K. Nakanishi, H. Tsutsui, H. Iwai and S. Akira et al., 2005. A novel caspase-1/toll-like receptor 4-independent pathway of cell death induced by cytosolic Shigella in infected macrophages. J. Biol. Chem., 280: 14042-14050. DOI: $10.1074 /$ jbc.M414671200

Takeuchi, O., K. Takeda, K. Hoshino, O. Adachi and T. Ogawa et al., 2000. Cellular responses to bacterial cell wall components are mediated through MyD88dependent signaling cascades. Int. Immunol., 12: 113-117. PMID: 10607756

Taneja, N., 2007. Changing epidemiology of shigellosis and emergence of ciprofloxacin-resistant Shigellae in India. J. Clin. Microbiol., 45: 678-9. DOI: 10.1128/JCM.02247-06

Tesh, V.L., B. Ramegowda and J.E. Samuel, 1994. Purified Shiga-like toxins induce expression of proinflammatory cytokines from murine peritoneal macrophages. Infect. Immunol., 62: 5085-5094. PMID: 7927791

Toussi, D.N., X. Liu and P. Massari, 2012. The FomA porin from Fusobacterium nucleatum is a Tolllike receptor 2 agonist with immune adjuvant activity. Clin. Vaccine Immunol., 19: 1093-1101. DOI: 10.1128/CVI.00236-12

Turbyfill, K.R., A.B. Hartman and E.V. Oaks, 2000. Isolation and characterization of a Shigella flexneri invasin complex subunit vaccine. Infect. Immunol., 68: 6624-6632. DOI: 11083774 
Watson, C., 2001. Death from multi-resistant shigellosis in Fiji Islands. Pac. Health Dial., 8: 99-102. PMID: 12017845

Way, S.S., A.C. Borczuk, R. Dominitz and M.B. Goldberg, 1998. An essential role for gamma interferon in innate resistance to Shigella flexneri infection. Infect. Immunol., 66: 1342-1348. PMID: 9529051

Wetzler, L.M., Y. Ho and H. Reiser, 1996. Neisserial porins induce $\mathrm{B}$ lymphocytes to express costimulatory B7-2 molecules and to proliferate. J. Exp. Med., 183: 1151-1159. PMID: 8642257
Witkowska, D., A. Czarny and M. Mulczyk, 1986. Humoral response in mice immunized with outer membrane proteins of Shigella flexneri. Arch. Immunol. Ther. Exp., 34: 499-504. PMID: 3296993

WHO, 1979. Intestinal immunity and vaccine development: A WHO memorandum. Bull. WHO, 57: 719-734.

WHO, 2005. Guidelines for the control of shigellosis, including epidemics due to Shigella dysenteriae type 1. WHO Library Cataloguing-in-Publication Data. 